\title{
ANALISIS KARAKTERISTIK KATALIS PERTAMINA UNTUK PROSES HYDROTREATING KEROSIN MENJADI AVTUR
}

\author{
THE ANALYSIS OF PERTAMINA CATALYST CHARACTERISTICS FOR KEROSENE \\ HYDROTREATING PROCESS INTO AVIATION FUEL
}

\author{
Euis Kusniawati ${ }^{1)}$, Ineke Febrina Anggraini ${ }^{2)}$, Riko Saputra ${ }^{3)}$ \\ ${ }^{1,2,3)}$ Program Studi Teknik Analisis Laboratorium Migas Politeknik Akamigas Palembang \\ Corresponding Author E-mail: euis@pap.ac.id
}

\begin{abstract}
Aviation fuel (Aviation Turbine) is fuel produced from kerosene with more strict specifications. Addition to that, some pollutant inside kerosene such as sulfur $(\mathrm{S})$ and Nitrogen $(\mathrm{N})$ need removing, so hydro-treating process is needed to remove pollutant with the help of catalyst. The process of aviation fuel manufacturing from kerosene so far has been using imported catalyst, so a research of catalyst production is now being conducted. Pertamina's catalyst production result must be checked in order to fulfill certain specifications. Therefore, catalyst characteristics need to be done. Catalyst characteristics were carried out by analyzing crystal's shapes, diameter, bulk density, mechanical power, and crystal types. After the characterization was completed, it was found out that the catalyst sample had trilobe shape, with $1.528 \mathrm{~mm}$ diameter, $0.6880 \mathrm{~g} / \mathrm{ml}$ bulk density, $112.45 \mathrm{~N}$ of mechanical power, and catalyst support was $\gamma$-Al2O3. From this research, it was concluded that the crystal shape and type from catalyst have fulfilled the specification standard, meanwhile the diameter, bulk density and mechanical power have not fulfilled the standard yet.
\end{abstract}

Keywords : Avtur, Catalyst, Hydro-Treating.

\begin{abstract}
Abstrak: Avtur (Aviation Turbine) merupakan bahan bakar yang dihasilkan dari kerosin dengan spesifikasi yang diperketat. Selain itu, pengotor yang terdapat pada kerosin seperti belerang $(S)$ dan nitrogen $(N)$ perlu dihilangkan, sehingga proses hydrotreating diperlukan untuk menghilangkan pengotor dengan bantuan katalis. Proses pembuatan avtur dari kerosin selama ini menggunakan katalis impor, maka saat ini dilakukan penelitian terkait pembuatan katalis. Hasil produksi katalis pertamina harus diperiksa agar dapat memenuhi spesifikasi. Sehingga, karakteristik katalis perlu dilakukan. Karakteristik katalis dilakukan dengan menganalisis bentuk, diameter, bulk density, kekuatan mekanik, dan jenis kristal. Setelah dilakukan karakterisasi diketahui bahwa sampel katalis memiliki bentuk trilobe, diameter 1,528 mm, bulk density 0,6880 g/ml, kekuatan mekanik 112,45 N, penyangga katalis merupakan $\gamma-\mathrm{Al}_{2} \mathrm{O}_{3}$. Dari penelitian ini, disimpulkan bahwa bentuk dan jenis kritsal dari katalis telah memenuhi standar spesifikasi, sedangkan untuk diameter, bulk density dan kekuatan mekanik belum standar spesifikasi.
\end{abstract}

Kata kunci : Avtur, Hydrotreating, Katalis.

\section{PENDAHULUAN}

\subsection{Latar Belakang}

Avtur (Aviation Turbine) merupakan salah satu bahan bakar yang dihasilkan dari kerosin dengan spesifikasi yang diperketat seperti titik uap dan titik beku. Selain itu, pengotor yang terdapat pada kerosin seperti belerang (S) dan nitrogen (N) perlu dihilangkan. Pengotor ini menyebabkan masalah yang cukup serius bagi lingkungan karena menghasilkan gas polutan berupa $\mathrm{SO}_{2}$ dan $\mathrm{NO}_{2}$ yang berakibat pada penurunan kualitas avtur, sehingga proses hydrotreating diperlukan untuk menghilangkan pengotor dengan bantuan katalis.
Katalis merupakan suatu senyawa yang dapat meningkatkan laju reaksi tetapi tidak terkonsumsi oleh reaksi. Peningkatan kecepatan reaksi terjadi karena katalis menurunkan energi aktivasi reaksi tersebut. Energi aktivasi adalah energi minimum yang dibutuhkan oleh suatu sistem agar reaksi dapat berjalan dan menghasilkan suatu produk (Sucipto, 2019). Katalis akan bekerja dengan mengantarkan reaktan melalui jalan alternatif yang memiliki energi aktivasi yang lebih rendah untuk membentuk suatu produk.Proses pembuatan avtur dari kerosin selama ini menggunakan katalis impor. Hal ini mengakibatkan meningkatnya biaya produksi avtur. Oleh karena itu, saat ini dilakukan 
penelitian terkait pembuatan katalis yang akan digunakan dalam proses pengolahan avtur di refinery unit. Hasil produksi katalis pertamina ini harus diperiksa agar mengetahui performa dan kualitasnya selalu terjaga. Sehingga, analisis spesifikasi katalis perlu dilakukan agar dapat memenuhi standar.

\subsection{Batasan Masalah}

Batasan masalah penelitian ini adalah untuk mengetahui karakterisasi dari katalis dengan menganalisis bentuk, diameter (size), bulk density, kekuatan mekanik dan jenis kristal.

\subsection{Tujuan Penelitian}

Tujuan dilaksanakannya penelitian ini adalah untuk mengetahui karakterisasi dari katalis dengan menganalisis bentuk, diameter (size), bulk density, kekuatan mekanik dan jenis kristal.

\subsection{Manfaat Penelitian}

Manfaat dilaksanakannya penelitian ini adalah dapat mengetahui karakterisasi dari katalis dengan menganalisis bentuk, diameter (size), bulk density, kekuatan mekanik dan jenis kristal.

\section{TEORI DASAR}

\subsection{Katalis}

Katalis adalah suatu zat yang dapat meningkatkan kecepatan reaksi terhadap suatu kesetimbangan tanpa adanya zat katalis yang dikonsumsi (Jacques, 2017). Katalis ikut terlibat pada suatu reaksi tetapi akan terbentuk kembali seperti semula diakhir reaksi, dengan demikian katalis tidak memberikan tambahan energi pada sistem dan secara termodinamika tidak dapat mempengaruhi kesetimbangan (Campbell, 2004). Katalis akan mengantarkan reaktan melalui jalan alternatif yang memiliki kondisi lebih lunak (temperatur dan tekanan lebih rendah). Tanpa adanya katalis, suatu reaksi akan berjalan lambat karena reaksi akan membutuhkan suhu dan tekanan yang tinggi (Ramadhan dan Rahardja, 2019). Penggunaan jalur alternatif dengan kinetika yang lebih baik menyebabkan terjadinya penurunan energi aktivasi. Energi aktivasi adalah energi minimum yang dibutuhkan oleh suatu sistem agar reaksi dapat berjalan dan menghasilkan suatu produk (Sucipto, 2019).

Katalis bersifat spesifik, artinya katalis hanya dapat bekerja pada reaksi kimia tertentu. Misal, suatu katalis dapat berperan dalam reaksi desulfurisasi, namun kurang baik dalam reaksi denitrogenasi, hal ini berkaitan dengan sifat fisika dan kimia katalis tersebut. Kriteria yang dipertimbangkan dalam pemilihan katalis untuk digunakan pada suatu reaksi adalah aktivitas katalis, selektivitas katalis, stabilitas katalis dalam kondisi operasi, peracunan katalis, deaktivasi katalis oleh produk, hilangnya aktivitas akibat penguapan dan transformasi kristalografi (Lestari, 2012).

\subsection{Komponen Penyusun Katalis}

Katalis disusun oleh 3 komponen yakni situs aktif, penyangga atau support dan promotor (Harjito, 2011). Situs aktif diisi oleh logam yang merupakan tempat reaksi berlangsung. Umumnya, logam yang digunakan adalah logam transisi karena memiliki orbital d yang kosong atau adanya elektron tunggal yang akan disumbangkan pada molekul reaktan untuk membentuk ikatan baru. Luas permukaan situs aktif mempengaruhi kinerjanya, semakin besar luas permukaan maka kinerja katalis pun semakin baik (Djawa, 2016).

Penyangga atau support adalah tempat logam aktif didispersikan. Fungsi utama dari penyangga adalah untuk menjaga agar luas permukaan komponen aktif tetap besar. Fungsi lain dari penyangga adalah menghasilkan kekuatan mekanik dan stabilitas panas dari suatu bahan katalis yang rapuh. Promotor adalah bahan yang apabila ditambahkan walaupum dalam jumlah yang sedikit menghasilkan aktivitas yang diinginkan, selektivitas, atau efek stabilitas (Rahman, 2009). Zat ini ditambahkan dengan tujuan untuk meningkatkan kinerja katalis.

\subsection{Jenis-jenis Katalis}

Berdasarkan jenisnya, katalis dibagi menjadi 2, yaitu katalis homogen dan katalis heterogen. Katalis homogen adalah katalis yang mempunyai fase sama dengan fase reaktan dan fase produk reaksi. Katalis 
homogen mempunyai aktivitas dan selektivitas tinggi, tidak mudah teracuni oleh keberadaan pengotor, mudah dioperasikan, mudah dimodifikasi, dan mudah untuk dipelajari. Kelemahan dari katalis homogen diantaranya sulit dipisahkan dari campuran reaksi dan membutuhkan biaya yang mahal, kurang stabil pada suhu tinggi, limbah yang dihasilkan berbahaya bagi lingkungan, dan bersifat korosif.

Katalis heterogen adalah katalis yang memiliki fase berbeda dengan fase reaktannya (Djawa, 2016). Katalis heterogen biasanya menggunakan katalis padatan dimana interaksi terjadi dipermukaan padatan/gas atau cairan/padatan. Aktivitas katalis ada di permukaan pori padatan katalis. Mekanisme yang terjadi pada katalis heterogen melibatkan proses adsorpsi dan desorpsi (Reza, 2017). Menurut Augustine (1996) reaksi katalisis heterogen memiliki tahapan-tahapan yang lebih kompleks dibandingkan dengan reaksi katalisis homogen. Hal ini terjadi karena pada reaksi katalisis heterogen katalis tidak terdistribusi merata ke dalam media reaksi. Sifat-sifat katalis heterogen yaitu tahan dan stabil pada suhu yang relatif tinggi, mudah dipisahkan, konstruksinya sederhana, umur katalis yang panjang, dan mudah teracuni.

\subsection{Bentuk-bentuk Katalis}

Katalis memiliki bentuk beragam. Bentuk katalis disesuaikan dengan kebutuhan pada suatu reaktor karena memberikan pengaruh tekanan dan temperatur yang berbeda (Hartaman, 2011). Selain itu, bentuk katalis pun akan mempengaruhi kecepatan selama proses katalisis. Ragam bentuk katalis diantaranya cylinder (silinder), hollow, trilobe, cylcut, daisy, dan 7-hole.

Hydroprocessing adalah proses hidrogenasi katalitik dengan menambahkan hidrogen ke dalam umpan. Hydroprocessing dibagi menjadi dua kelompok berdasarkan tujuannya, yaitu hydrocracking dan hydrotreating.

\section{Hydrocracking}

Hydrocracking adalah gabungan 2 tahapan proses, yaitu catalytic cracking dan hidrogenasi berupa pemutusan ikatan karbonkarbon pada molekul-molekul besar untuk menghasilkan produk yang diinginkan, proses ini akan menyebabkan penurunan besar pada titik didih. Hydrocracking bekerja pada suhu dan tekanan tinggi namun lebih rendah dibandingkan catalytic cracking, dalam rentang $200-400^{\circ} \mathrm{C}$ dan tekanan hidrogen sebesar 1-10 MPa tergantung pada bahan baku dan jenis reaksi yang diinginkan. Katalis yang biasanya digunakan adalah platina, tungsten, paladium, dan/atau nikel.

\section{Hydrotreating}

Proses ini termasuk dalam proses hidrogenasi katalitik yang digunakan dalam pemurnian produk tanpa mengalami perubahan besar dari rentang titik didih (Trisunaryanti, 2018). Gas hidrogen direaksikan dengan umpan pada temperatur yang sama dengan hydrocracking, namun tekanannya lebih rendah untuk meminimalkan terjadinya dekomposisi termal. Proses ini dibutuhkan untuk meningkatkan kualitas produk akhir. Unsur-unsur yang tidak diingikan dihilangkan seperti sulfur, nitrogen, oksigen dan halidahalida, dan sisa logam. Pengotor ini menyebabkan masalah yang cukup serius bagi lingkungan karena menghasilkan gas polutan berupa $\mathrm{SO}_{2}$ dan $\mathrm{NO}_{2}$. Katalis yang sering digunakan pada proses hydrotreating adalah $\mathrm{Co}-\mathrm{Mo} / \mathrm{Al}_{2} \mathrm{O}_{3}$ dan $\mathrm{Ni}-\mathrm{Mo} / \mathrm{Al}_{2} \mathrm{O}_{3}$.

\subsection{Katalis Hydrotreating}

Katalis hydrotreating terdiri dari oksida logam molibdenum (Mo) atau tungsten (W) dan kobalt (Co) atau nikel (Ni) dalam penyangga $\gamma-\mathrm{Al}_{2} \mathrm{O}_{3}$. Katalis juga diberi zat aditif fosfor (P) yang diketahui dapat meningkatkan aktivitas katalis dengan meningkatkan dispersi Mo dalam penyangga (Kamilia, 2018). Katalis hydrotreating miliki PT Pertamina (PERSERO) mengandung sisi aktif berupa $\mathrm{Ni}-\mathrm{Mo}$ dan $\gamma-\mathrm{Al}_{2} \mathrm{O}_{3}$ sebagai penyangga dengan promotor P. Spesifikasi katalis hydrotreating milik PT Pertamina (Persero) dapat dilihat pada Tabel 2.1. 
Tabel 2.1 Spesifikasi Katalis Hydrotreating PT Pertamina (Persero)

\begin{tabular}{|l|c|}
\hline \multicolumn{1}{|c|}{ Parameter } & Range \\
\hline Sifat Kimia & $>15 \% \mathrm{~b} / \mathrm{b}$ \\
\hline Mo (sebagai $\left.\mathrm{MoO}_{3}\right)$ & $>3 \% \mathrm{~b} / \mathrm{b}$ \\
\hline $\mathrm{Ni}($ sebagai $\mathrm{NiO})$ & $>3 \% \mathrm{~b} / \mathrm{b}$ \\
\hline Fosfor & $\gamma-\mathrm{Al}_{2} \mathrm{O}_{3}$ \\
\hline Penyangga & \\
\hline Sifat Kisik & Trilobe \\
\hline Bentuk & $1,50 \pm 0,05 \mathrm{~mm}$ \\
\hline Diameter & $0,6 \mathrm{~g} / \mathrm{ml}$ \\
\hline Bulk Density & $\mathrm{min} 7,0 \mathrm{~kg}$ \\
\hline Kekuatan Mekanik & $>150 \mathrm{~m}^{2} / \mathrm{g}$ \\
\hline Luas Permukaan & $>0,45 \mathrm{cc} / \mathrm{g}$ \\
\hline Volume Pori & $100 \AA$ \\
\hline Diameter Pori &
\end{tabular}

Sumber : Pertamina, 2019

\subsection{Kerosin dan Avtur (Aviation Turbine)}

Kerosin merupakan distilat pertengahan dari proses penyulingan minyak bumi, didefinisikan sebagai fraksi minyak bumi yang memiliki titik didih antara 145$300^{\circ} \mathrm{C}$. Kerosin dapat diproduksi melalui distilasi minyak mentah atau dari perengkahan fraksi berat minyak bumi. Kerosin merupakan campuran komplek dari senyawa rantai lurus dan bercabang, yang secara umum dapat dikategorikan menjadi tiga kelas: parafin $(55,2 \%)$, naften $(40,9 \%)$ dan aromatik $(3,9 \%)$. Kerosin mengandung sulfur sebesar 0,1-0,3\%.

Avtur (aviation turbine) merupakan bahan bakar yang dapat diperoleh dari hasil pengolahan minyak bumi, yang mempunyai range titik didih antara $150-300^{\circ} \mathrm{C}$, terdiri dari molekul hidrokarbon $\left(\mathrm{C}_{11}-\mathrm{C}_{15}\right)$ dan titik beku (freezing point) dibatasi maksimum $-47^{\circ} \mathrm{C}$ (Haidir, 2001). Avtur atau Jet A-1 adalah bahan bakar penerbangan untuk jenis pesawat bermesin turbin dan pesawat jet yang banyak digunakan dipenerbangan komersial. Bahan bakar ini berasal dari proses pengolahan fraksi kerosin yang mempunyai sifat pembakaran dan energi tinggi. Jenis kerosin telah dipilih sebagai bahan bakar untuk generasi pertama kali sebab mempunyai sifat pembakaran yang baik, rendah terhadap kebakaran, sehingga digunakan sebagai pengganti gasolin saat perang dunia.
Bahan bakar ini diperoleh dari proses pengolahan minyak bumi dengan komposisi tertentu baik dari proses distilasi maupun proses perengkahan. Avtur dituntut harus mempunyai nilai pembakaran yang tinggi, kualitas pembakaran tinggi, freezing point rendah, kandungan panas/berat tinggi, serta kandungan panas/volume rendah. Berdasarkan Keputusan Direktorat Jenderal Minyak dan Gas (Kepdirjenmigas) tahun 2011 mengenai standar mutu (spesifikasi) bahan bakar avtur, beberapa diantaranya dilampirkan pada Tabel 2.2.

Tabel 2.2 Standar Mutu Bahan Bakar Avtur

\begin{tabular}{|l|l|}
\hline \multicolumn{1}{|c|}{ Sifat } & \multicolumn{1}{|c|}{ Batasan } \\
\hline Penampilan visual & $\begin{array}{l}\text { Jernih, terang dan } \\
\text { bebas dari zat padat } \\
\text { dan air tidak terlarut } \\
\text { pada suhu kamar }\end{array}$ \\
\hline Total sulfur & Maks. 0,30\% m/m \\
\hline Flash point (Titik Nyala) & Min. $38^{\circ} \mathrm{C}$ \\
\hline $\begin{array}{l}\text { Freezing point (Titik } \\
\text { Beku) }\end{array}$ & Maks. $-47^{\circ} \mathrm{C}$ \\
\hline
\end{tabular}

Sumber : Kepdirjenmigas, 2011

\subsection{Karakterisasi Katalis}

Katalis yang telah dibuat perlu diuji apakah struktur katalis tersebut sudah sesuai dengan struktur yang diinginkan atau tidak. Struktur katalis didesain berdasarkan kinerja yang diharapkan pada saat penggunaan katalis. Pengujian ini biasa disebut dengan karakterisasi. Bagian yang paling penting dalam karakterisasi katalis adalah pemilihan metode karakterisasi katalis yang tepat.

Teknik pemilihan metode katalis sangat bergantung pada keperluan atau kepentingannya secara ilmiah dan tenik, biaya karakterisasi dan kemudahan akses pelaratan. Secara garis besar, teknik karakterisasi katalis dapat dibagi menjadi beberapa macam berdasarkan sifat - sifat yan akan diteliti (Istadi, 2004).

\section{METODOLOGI PENELITIAN}

\subsection{Waktu dan Tempat Penelitian}

Kegiatan pengambilan data dan penelitian ini dilaksanakan pada tanggal 17 Februari 2020 s.d 17 Maret 2020 di Laboratorium 
Catalyst \& Material Research and Technology Center (RTC) PT Pertamina (Persero).

\subsection{Teknik Pengumpulan Data}

Proses pengumpulan data dilakukan dengan metode sebagai berikut :

1. Observasi

Data yang diperoleh merupakan data dari pengamatan secara langsung di lapangan saat melaksanakan penelitian sesuai dengan prosedur kerja yang telah ditentukan.

2. Wawancara

Data yang diperoleh juga didapat dari kegiatan tanya jawab secara langsung dengan pembimbing atau analis di Laboratorium Catalyst \& Material Research and Technology Center (RTC) PT Pertamina (Persero).

3. Referensi

Data-data yang diperoleh dalam penyusunan laporan tugas akhir bersumber dari literatur yang berhubungan dan bersesuaian, baik literatur dari Laboratorium Catalyst \& Material Research and Technology Center (RTC) PT. Pertamina (Persero) maupun dari luar, beberapa buku, laporan tugas akhir dan website.

\subsection{Prosedur Kerja}

1. Penentuan diameter
Diameter
(size)
ditentukan

menggunakan jangka sorong digital. Tombol "ON" pada jangka sorong ditekan lalu sampel diambil dan bagian diameter diposisikan pada bagian rahang luar jangka sorong selanjutnya nilai diameter dibaca pada monitor jangka sorong. Penentuan dilakukan sebanyak 50 kali ulangan.

\section{Penentuan bulk density}

Bulk density ditentukan menggunakan Bulk density apparatus. Wadah sampel dibersihkan lalu ditimbang. Selanjutnya sampel dimasukan secara memutar ke dalam wadah hingga penuh. Setelah penuh, permukaan sampel diratakan lalu ditimbang. Penentuan dilakukan sebanyak 3 kali ulangan.
3. Penentuan Kekuatan Mekanik

Kekuatan mekanik ditentukan menggunakan Crush BK 300. Penentuan ini dilakukan dengan 2 tahapan, yaitu preparasi sampel dan analisis sampel.

a. Preparasi sampel

Sampel dipanaskan pada suhu $400^{\circ} \mathrm{C}$ selama 3 jam lalu didinginkan pada suhu ruang di dalam desikator.

b. Analisis sampel

Sampel diambil menggunakan pinset dan diletakan ditengah piston lalu piston bagian atas diturunkan hingga mendekati sampel. Selanjutnya, tombol "UP" ditekan untuk menaikan piston bagian bawah hingga sampel hancur. Nilai yang tertera pada monitor instrument dicatat. Penentuan dilakukan sebanyak 50 kali ulangan.

4. Penentuan jenis kristal

Jenis kristal ditentukan menggunakan PANalytical Empyrean XRD (X-Ray Diffraction). Penentuan ini dilakukan dengan 2 tahapan, yaitu preparasi sampel dan analisis sampel.

a. Preparasi sampel

Sampel digerus hingga halus menggunakan mortar lalu sampel yang telah halus dituang kedalam sample holder yang sudah dibersihkan dengan aseton selanjutnya diratakan dengan kaca preparat. Sampel yang telah rata siap diuji.

b. Analisis sampel

Tombol "UNLOCK DOOR" ditekan dan pintu XRD dibuka lalu sampel dimasukan pada port sampel dan pintu ditutup dengan rapat. Menu "MEASURE" dipilih dan klik "PROGRAM" lalu pilih program "SLOW SCAN 90" dan diklik "OK".

\section{HASIL DAN PEMBAHASAN \\ 4.1 Bentuk Katalis}

Bentuk katalis dapat diamati langsung secara visual. Sampel LOT 19, LOT 23, LOT 26 dan LOT 28 memiliki bentuk yang sama, yaitu trilobe. Katalis memiliki variasi bentuk dan ukuran. Hal ini bertujuan untuk spesifikasi proses yang akan dilakukan oleh katalis tersebut. Katalis Pertamina adalah katalis 
untuk proses hydrotreating. Katalis hydrotreating memiliki sifat antara lain memiliki komponen aktif Mo, promotor $\mathrm{Ni}$, memiliki bentuk tri-lobe, dan memiliki ukuran diameter $\pm 1 \mathrm{~mm}$.
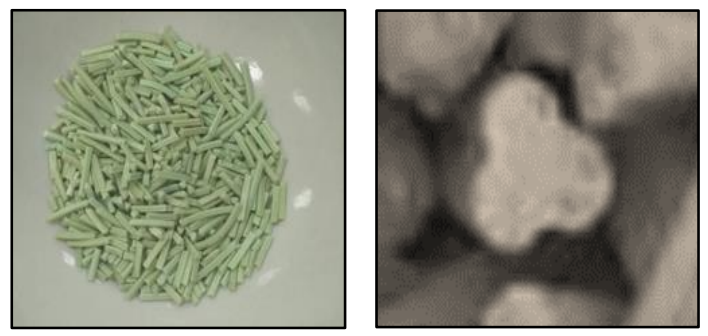

Gambar 4.1 Bentuk Tri-lobe Sampel Katalis

\subsection{Penentuan Diameter (Size)}

Diameter katalis diukur menggunakan jangka sorong digital sebanyak 50 kali pengulangan. Katalis dibuat dengan spesifikasi diameter sebesar $1,50 \pm 0,05 \mathrm{~mm}$. Grafik distribusi diameter tiap sampel dibuat untuk melihat penyebaran diameter hasil pengukuran sehingga dapat dilihat keseragaman diameter katalis yang diproduksi. Pengukuran diameter sampel LOT 19 memiliki distribusi 1,43-1,64 $\mathrm{mm}$ dengan range $0,21 \mathrm{~mm}$. Sebanyak 24 katalis dari 50 katalis yang diukur memiliki diameter di luar spesifikasi yang ditentukan (offspec). Rerata diameter sebesar 1,53 mm dan nilai relative standard deviation (RSD) $3,7 \%$.

Pengukuran diameter sampel LOT 23 memiliki distribusi 1,45-1,63 $\mathrm{mm}$ dengan range $0,18 \mathrm{~mm}$. Sebanyak 14 katalis dari 50 katalis yang diukur memiliki diameter diluar spesifikasi yang ditentukan (offspec). Rerata diameter sebesar 1,54 dan nilai relative standard deviation (RSD) 2,6\%.

Pengukuran diameter sampel LOT 26 memiliki distribusi 1,46-1,58 $\mathrm{mm}$ dengan range $0,12 \mathrm{~mm}$. Sebanyak 11 katalis dari 50 katalis yang diukur memiliki diameter diluar spesifikasi yang ditentukan (offspec). Rerata diameter sebesar 1,52 dan nilai relative standard deviation (RSD) 2,3\%.

Pengukuran diameter sampel LOT 28 memiliki distribusi 1,43-1,61 $\mathrm{mm}$ dengan range $0,18 \mathrm{~mm}$. Sebanyak 18 katalis dari 50 katalis sampel yang diukur memiliki diameter di luar spesifikasi yang ditentukan (offspec). Rerata diameter sebesar 1,53 dan nilai relative standard deviation (RSD) 3,0\%.

\subsection{Penentuan Bulk Density}

Analisis ini memiliki fungsi untuk mengetahui nilai bulk density dari sampel katalis LOT 19, LOT 23, LOT 26 dan LOT 28. Bulk density merupakan perbandingan antara massa partikel dengan jumlah volume padatan, pori-pori di dalam partikel dan ruang kosong antar partikel di dalam bed. Nilai bulk density akan digunakan sebagai acuan untuk berapa banyak katalis yang akan dimasukkan ke dalam suatu kilang dengan volume tertentu agar proses katalisis berjalan dengan efisien (Istadi, 2011). Penentuan bulk density dapat dilakukan dengan dua metode yaitu tapped dan untapped. Metode tapped adalah saat wadah silinder berisi sampel, diketuk-ketuk agar sampel bisa dimuat lebih banyak didalam wadah. Sampel katalis LOT 19, LOT 23, LOT 26 dan LOT 28 diukur dengan metode untapped, pengukuran menggunakan wadah silinder dengan volume $92,87 \mathrm{ml}$. Nilai bulk density sampel dapat dilihat pada Tabel 4.1.

Tabel 4.1 Bulk Density LOT 19, LOT 23, LOT 26, LOT 28

\begin{tabular}{|l|c|c|}
\hline Sampel & $\begin{array}{c}\text { Bulk Density } \\
(\mathrm{g} / \mathrm{ml})\end{array}$ & RSD (\%) \\
\hline LOT 19 & 0,6979 & $1,26 \%$ \\
\hline LOT 23 & 0,6950 & $1,34 \%$ \\
\hline LOT 26 & 0,6865 & $1,20 \%$ \\
\hline LOT 28 & 0,6786 & $2,30 \%$ \\
\hline Rerata & 0,6880 & \\
\hline
\end{tabular}

Berdasarkan Tabel 4.1, nilai RSD keempat sampel di bawah 5\% sehingga data pengukuran bulk density dapat diterima. Spesifikasi bulk density yang ditentukan adalah 0,6 $\pm 0,05 \mathrm{~g} / \mathrm{ml}$, ditinjau dari Tabel 2.1 Spesifikasi katalis hydrotreating PT Pertamina. Sehingga diketahui bahwa nilai bulk density dari keempat sampel diluar spesifikasi yang telah ditentukan (offspec), hal ini dapat menyebabkan sejumlah katalis tidak bisa masuk ke dalam reaktor. Dengan demikian, berat jenis katalis berpengaruh pada efisiensi penggunaan katalis. 


\subsection{Penentuan Kekuatan Mekanik}

Analisis ini dilakukan untuk mengetahui kekuatan mekanik dari katalis terhadap tekanan yang diberikan ketika berada didalam reaktor. Analisis ini dilakukan dengan cara memberikan tekanan secara vertikal hingga sampel mengalami kehancuran. Nilai kekuatan mekanik akan terbaca pada alat dalam satuan Newton kemudian dikonversikan dalam satuan $\mathrm{kg}$.

Sebelum dianalisis, sampel katalis terlebih dahulu dikeringkan pada suhu $400^{\circ} \mathrm{C}$ selama 3 jam kemudian didinginkan dalam desikator. Tujuannya adalah untuk menghilangkan kadar air yang masih tersisa pada penyangga katalis yang akan dianalisis. Keberadaan air dalam katalis dapat menyababkan katalis lebih rapuh sehingga kekuatan mekanik yang teranalisa akan dihasilkan nilai faktor ketidakpastian yang besar.

Pengukuran kekuatan mekanik sampel katalis LOT 19 memiliki distribusi $5,9-21,5 \mathrm{~kg}$ dengan range $15,6 \mathrm{~kg}$. Sebanyak 2 katalis dari 50 katalis yang diukur memiliki diameter diluar spesifikasi yang ditentukan (offspec). Rerata kekuatan mekanik sebesar 12,69 kg.

Pengukuran kekuatan mekanik sampel LOT 23 memiliki distribusi 6,0-20,7 $\mathrm{kg}$ dengan range $14,7 \mathrm{~kg}$. Sebanyak 2 katalis dari 50 katalis yang diukur memiliki diameter diluar spesifikasi yang ditentukan (offspec). Rerata kekuatan mekanik sebesar 11,9 kg.

Pengukuran kekuatan mekanik sampel LOT 26 memiliki distribusi 4,4-17,6 kg dengan range 13,2 kg. Sebanyak 9 katalis dari 50 katalis yang diukur memiliki diameter diluar spesifikasi yang ditentukan (offspec). Rerata kekuatan mekanik sebesar 10,2 kg.

Pengukuran kekuatan mekanik sampel LOT 28 memiliki distribusi 4,5-15,7 kg dengan range $11,2 \mathrm{~kg}$. Sebanyak 17 katalis dari 50 katalis yang diukur memiliki diameter diluar spesifikasi yang ditentukan (offspec). Rerata kekuatan mekanik sebesar 9,0 kg.

\subsection{Penentuan Jenis Kristal}

Struktur kristal katalis diuji dengan menggunakan X-Ray Diffraction (XRD). Hasil analisis berupa difraktogram yang menyatakan hubungan antara sudut difraksi di sumbu-X dan intensitas (relative intensity) di sumbu-Y, membentuk pola puncak (peak) yang karakteristik untuk tiap jenis kristal. Penggunaan sinar- $X$ untuk analisis struktur padatan didasarkan atas fakta bahwa gelombang dapat mengalami fenomena difraksi pada saat berinteraksi dengan sistem (pusat difraksi) yang memiliki jarak celah (kisi) sesuai dengan panjang gelombang sinar pendifraksi. Sinar-X monokromatik direfleksikan sesuai dengan panjang gelombang sinar pendifraksi. Sinar- $\mathrm{X}$ monokromatik direfleksikan oleh sampel dengan garis difraksi yang dihasilkan dari dimensi bidang kristal yang berulang. Tiap tiap kristal memberikan pola khusus, sehingga posisi puncak dalam difraktgram merupakan petunjuk akan kehadiran senyawa tertentu. Keberadaan jenis kristal ditentukan menggunakan XRD. Kristal ini merupakan penyangga katalis berupa berupa $\gamma-\mathrm{Al}_{2} \mathrm{O}_{3}$. Berdasarkan difraktogram keempat sampel pada Gambar 4.2. Dapat diketahui bahwa keempat sampel adalah kristal dengan tingkat kristalinitas yang tergolong rendah. Hal ini ditunjukan dari pola difraktogram yang sudah membentuk peak yang melebar dan terdapat gangguan (noise) yang memunculkan puncakpuncak tidak teratur.

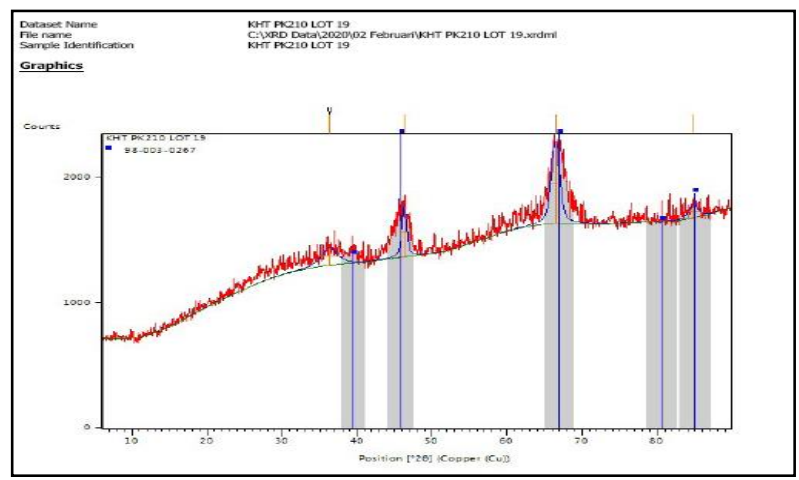

Gambar 4.2 Hasil Difraktogram Sampel Katalis LOT 19

Sampel katalis LOT 19 dapat dilihat bahwa sampel memunculkan peak dengan intensitas tertinggi sebesar 398.52 cts. Suatu sampel dengan kristalinitas yang tinggi akan 
memberikan intensitas peak yang tinggi dan tajam. Nilai kemiripan difraktogram sampel dengan difraktogram suatu senyawa dinyatakan dalam suatu score. Sampel diketahui mengandung Alumunium OxideGamma dengan skor kemiripan 75.

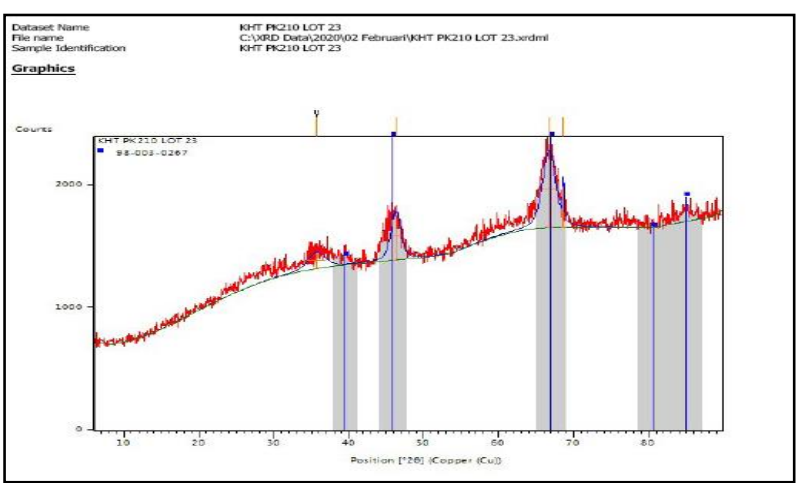

Gambar 4.3 Hasil Difraktogram Sampel Katalis LOT 23

Sampel katalis LOT 23 memunculkan peak dengan intensitas tertinggi sebesar 624.90 cts. Suatu sampel dengan kristalinitas yang tinggi akan memberikan intensitas peak yang tinggi dan tajam. Nilai kemiripan difraktogram sampel dengan difraktogram suatu senyawa dinyatakan dalam suatu score. Sampel diketahui mengandung Alumunium Oxide-Gamma dengan skor kemiripan 81 .

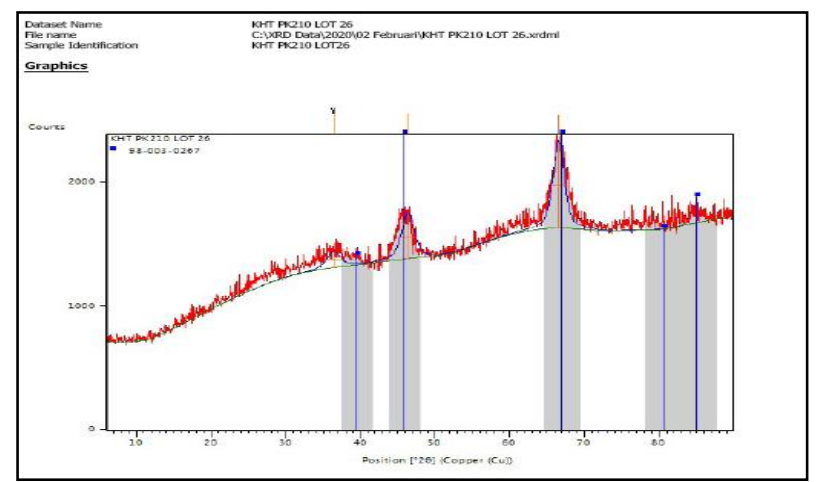

Gambar 4.4 Hasil Difraktogram Sampel Katalis LOT 26

Untuk sampel katalis LOT 26 dapat dilihat bahwa sampel memunculkan peak dengan intensitas tertinggi sebesar 697.79 cts. Suatu sampel dengan kristalinitas yang tinggi akan memberikan intensitas peak yang tinggi dan tajam. Nilai kemiripan difraktogram sampel dengan difraktogram suatu senyawa dinyatakan dalam suatu score. Sampel diketahui mengandung Alumunium OxideGamma dengan skor kemiripan 83.

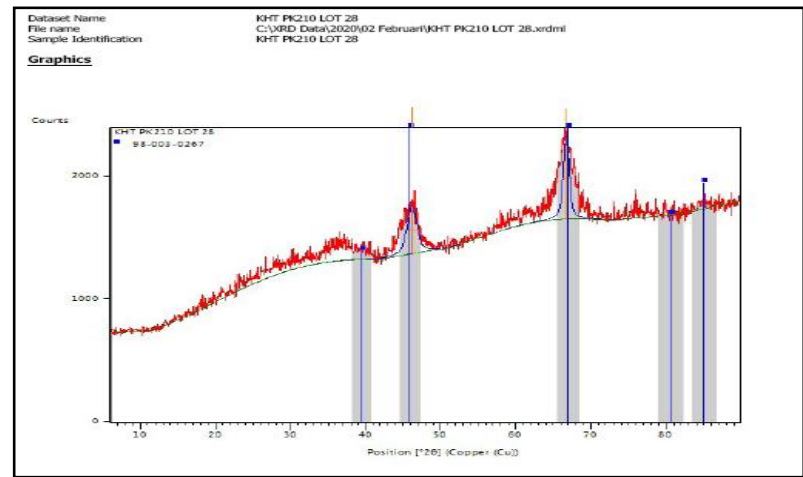

Gambar 4.3 Hasil Difraktogram Sampel Katalis LOT 28

Kemudian untuk sampel katalis LOT 28 dapat dilihat bahwa sampel memunculkan peak dengan intensitas tertinggi sebesar 666.00 cts. Suatu sampel dengan kristalinitas yang tinggi akan memberikan intensitas peak yang tinggi dan tajam. Nilai kemiripan difraktogram sampel dengan difraktogram suatu senyawa dinyatakan dalam suatu score. Sampel diketahui mengandung Alumunium Oxide-Gamma dengan skor kemiripan 94.

Terdapat puncak yang muncul diluar puncak standar $\gamma-\mathrm{Al}_{2} \mathrm{O}_{3}$, puncak-puncak tersebut dapat berasal dari logam aktif dan pengotor dalam katalis. Penyangga $\gamma-\mathrm{Al}_{2} \mathrm{O}_{3}$ pada katalis ini mengandung fosfor sebagai zat aditif. Kandungan fosfor dalam penyangga tidak tampak pada pola difraksi. Tidak adanya puncak khas fosfor dalam alumina menunjukan bahwa fosfor terdispersi merata dan stabil dalam fase $\gamma-\mathrm{Al}_{2} \mathrm{O}_{3}$.

\section{KESIMPULAN DAN SARAN 5.1 Kesimpulan}

Berdasarkan hasil analisis karakteristik katalis untuk proses hydrotreating kerosin menjadi avtur diperoleh kesimpulan sebagai berikut:

1. Katalis Pertamina adalah katalis untuk proses hydrotreating. Bentuk tri-lobe, 
memiliki sifat antara lain memiliki komponen aktif Mo, promotor Ni.

2. Berdasarkan pengukuran diameter diperoleh rata-rata diameter seluruh sampel adalah 1,53 mm. Terdapat beberapa sampel LOT 19, LOT 23, LOT 26 dan LOT 28 yang memiliki nilai diameter diluar spesifikasi yang telah ditentukan yaitu $1,50 \pm 0,05 \mathrm{~mm}$.

3. Rata-rata bulk density dari sampel LOT 19, LOT 23, LOT 26 dan LOT 28 sebesar $0,6880 \mathrm{~g} / \mathrm{ml}$.

4. Hasil pengujian kekuatan mekanik diperoleh rerata keseluruhan sampel sebesar $11,5 \mathrm{~kg}$.

5. Dari sampel LOT 19, LOT 23, LOT 26 dan LOT 28 terdapat puncak yang muncul diluar puncak standar $\gamma-\mathrm{Al}_{2} \mathrm{O}_{3}$, puncakpuncak tersebut dapat berasal dari logam aktif dan pengotor dalam katalis.

6. Berdasarkan karakterisasi yang telah dilakukan dapat disimpulkan bahwa bentuk, jenis kristal, keempat sampel sesuai dengan standar spesifikasi, keempat sampel belum memenuhi standar spesifikasi diameter, bulk density, dan kekuatan mekanik.

\subsection{Saran}

Produksi katalis perlu ditinjau ulang supaya sifat fisik seperti diameter, bulk density, kekuatan mekanik katalis dapat memenuhi standar spesifikasi yang telah ditetapkan.

\section{DAFTAR PUSTAKA}

Djawa JPT. 2016. Sintesis dan Karakterisasi Katalis $\mathrm{Mg}_{1-\mathrm{x}} \mathrm{Zn}_{\mathrm{x}} \mathrm{FOH}$ Serta Aplikasinya Pada Reaksi Trimetilhidrokuinon dan Isofitol (Skripsi). Surabaya (ID): Institut Teknologi Sepuluh Nopember.

Fatoni, Zainuddin. 2014. Ketidakpastian Pengukuran. Palembang: Politeknik Akamigas Palembang.

Hasanuddin. 1998. Preparasi katalis $\mathrm{CuO} / \mathrm{ZnO} / \mathrm{SiO}_{2}$ dan interpretasinya terhadap hasil karakterisasi dengan menggunakan metode AAS, FTIR, XRD, dan AUTOSORB-
BET (Skripsi). Depok (ID) : Universitas Indonesia.

Istady. 2011. Teknologi Katalis untuk Konversi Energi: Fundamental dan Aplikasi. Yogyakarta (ID): Graha Ilmu.

Kamalia, Farah. 2016. Skripisi: Sintesis Katalis $\mathrm{NiMo} / \gamma-\mathrm{Al}_{2} \mathrm{O}_{3}, \mathrm{CoMo} / \gamma-\mathrm{Al}_{2} \mathrm{O}_{3}$, dan $\mathrm{CoNiMo} / \gamma-\mathrm{Al}_{2} \mathrm{O}_{3}$ Untuk Hidrodesulfurisasi Kerosin. Jakarta: UIN Syarif Hidayatullah

Lestari DY. 2012. Pemilihan Katalis yang Ideal. Prosiding Seminar Nasional Penelitian, Pendidikan, dan Penerapan MIPA 2012. Indonesia. Yogyakarta: Universitas Negeri Yogyakarta.

Oxtoby DW, Gillis HP, Campion A. Principles of Modern Chemistry $7^{\text {th }}$ Edition. New York (US): Brooks/Cole Cengange Learning.

Rahardja IB, Sukarman, Ramadhan AI. 2019. Analisis Kalori Biodiesel Crude Palm Oil (CPO) Dengan Katalis Abu Tandan Kosong Kelapa Sawit. Prosiding Seminar Nasional Sains dan Teknologi 2019. Bogor: Universitas Muhamadiyah Jakarta.

Reza MAD. 2017. Pembuatan dietil eter dengan katalis berbasis $\gamma-\mathrm{Al}_{2} \mathrm{O}_{3}$ dipromote dengan logam $\mathrm{Cr}$ dan Co dalam reaktor fix bed (Tesis). Surabaya: Institut Teknologi Sepuluh Nopember.

Sucipto L, Rustiawan W, Jumaeri, Alighiri D, Wahyuni S. 2019. Pengaruh temperatur dan rasio $\mathrm{H}_{2}$ /hidrokarbon menggunakan katalis $\mathrm{CoMo} /-\mathrm{Al}_{2} \mathrm{O}_{3}$ pada hydrotreating combined gas oil. Indonesia Journal of Chemical Science. 8(3): 185-190.

Tsani, Fatimatuts. 2011. Preparasi dan Karakterisasi Katalis $\mathrm{NiMo} / \Gamma-\mathrm{Al}_{2} \mathrm{O}_{3}$ Untuk Sintesis Bahan Bakar Bio Dari Minyak Jarak Melalui Pirolisis Berkatalis.

Wu, D.F., et.al. 2006. Distribution of the Mechanical Strength of Solid Catalysts. Chemical Engineering Research and Design: 152-1157. 